\title{
Research on the asymmetric impact of EKOP model based on the concept of green development
}

\author{
Wang Jiawei ${ }^{1, *}$ \\ ${ }^{1}$ Yantai Institute of China Agricultural University, Yantai, China
}

\begin{abstract}
Green economy as a new development model, its development has risen to the national strategic level. And enterprises as the main body of economic activities should also keep pace with the times and take green development as their basic value orientation. Based on the EKOP model, this paper uses eight stocks in the A-share airline industry, selects three first-order indicators, namely human capital characteristics, board characteristics and equity structure characteristics, to represent corporate governance characteristics, and uses the probability of informed trading to represent the degree of information asymmetry, and studies the influence of corporate governance on information asymmetry. The aim is to explore the relevance of each factor asymmetry and use its findings to serve the development of the green economy model and promote the standardization of corporate governance.
\end{abstract}

\section{Introduction}

The degree of corporate information disclosure or insider trading, also known as information risk, is mainly measured indirectly or directly by domestic and foreign scholars using proxy variables or EKOP models. Their research shows that corporate governance situation or corporate governance structure is closely related to the degree of information asymmetry, and a higher level of corporate governance tends to disclose higher quality information, which can reduce the degree of information asymmetry in the capital market and thus reduce the cost of corporate financing [1].

In order to investigate whether corporate governance for airline companies is the main factor affecting corporate information risk, this paper mainly uses the EKOP model to measure information risk, and uses a linear regression model to measure the value of the main governance level affecting PIN.

\section{Enterprise Information Risk Measure- ment}

\subsection{Classical EKOP model and its improvement}

\subsubsection{Classic EKOP model}

Domestic and foreign scholars have used proxy variables such as turnover rate, fluctuations in cumulative excess return, and changes in relative trading volume to measure information asymmetry in Chengdu. The earliest model that can directly measure the information asymmetry measure, namely the EKOP model, was proposed by Easley et al. (1996).EASLEY et al. (1996) proposed an informed trading probability model (referred to as the EKOP model) based on the quote-driven market.The EKOP model was proposed based on the sequential trading model, and a mixed distribution approach of transaction-by-transaction was used to achieve informed The EKOP model is based on the sequential trading model, and the direct measurement of informed trading is achieved by a mixed distribution of transaction-bytransaction. The model is based on the probability of informed transactions-PIN, which later becomes an important indicator for measuring informa-tion asymmetry. In the EKOP model assumptions, trading is generated by the behavior of a group of potentially informed and uninformed traders [2]. The trading behavior is discrete between days and continuous within days. That is, the traders' behavior occurs on $\mathrm{i}=1,2, \ldots$ i discrete trading days, while within trading days, trading behavior takes place on a continuous time horizon.

The model assumes that informed trading occurs with probability $\alpha$ and uninformed trading probability event occurs with $(1-\alpha)$. If good news occurs, we denote the stock value as $\mathrm{V}+$, the stock value for bad news as $\mathrm{V}$--, and the stock value for no news occurrence as $\mathrm{V}^{*}$, obviously $\mathrm{V}+>\mathrm{V}^{*}>\mathrm{V}-$. Thus, if an informed trader observes a good signal, the action that maximizes profit is to buy the stock; conversely, he sells the stock.

\subsubsection{Improvements based on the daily PIN indicator}

In this paper, the PIN indicator is improved. The traditional PIN value of the daily probability of occurrence of informed transactions is $\alpha$, the message arrival rate is $\mu$, and the respective arrival rates of uninformed buyers and uninformed sellers of their prices

* Corresponding author: wangjw@cau.edu.cn 
are $\varepsilon$, which remain constant as fixed values over a certain period of time. This assumption does not correspond to reality, and we adjust the time window of the EKOP model in order to be closer to reality. The basis is that according to the theory of the EKOP model, the parameters of buy and sell order arrivals follow a Poisson distribution process and are independent of each other. Therefore, in this paper, the daily PIN values are estimated, subject to the daily operating hours of China's stock market, which are 9:30-11:30 and 13:00-15:00. On any trading day, the transaction volume of both buyers and sellers is recorded once every ten minutes as a time window and brought into the EKOP model to calculate the PIN values [3]. After a reasonable time segmentation, the transaction volume of both buyers and sellers is reduced and a more reasonable sample size is obtained, and 24 sets of data are obtained for the calculation of parameter $\theta$ each day. In addition, this paper also uses the split-pen test method to determine the direction of trade initiation, i.e., a rising stock price is a buyer-initiated trade, a falling stock price is a seller-initiated trade, and if the rise or fall is 0 , then the trade follows the direction of the previous trade initiation, and so on.

\subsection{PIN index estimation results and character- istics}

In this paper, we use the data of trading volume, up and down of every minute of China's listed companies from December 2, 2019 to January 23, 2020 as the sample data, and according to the nature of EKOP model, this paper uses the trading data of every minute of continuous bidding (9:00 to $11: 30$ and 13:00 to $15: 00$ ), which is aggregated in ten-minute increments, as the research object, and uses $\mathrm{R}$ for data processing to test the effect of corporate governance situation on information asymmetry. The data were obtained from the WAND database, and the missing values or missing data in the variables were excluded, leaving data for 69 stocks [4].

As shown in Figure 1, between December 2, 2019 and January 23,2020 , the probability of informed trading stays below 0.5 for most airline companies, except for Mountain Air B. The PIN values of all airline companies fluctuate steadily in different intervals, from which it can be inferred that the probability of informed trading is affected by the different governance levels of companies. The highest mean value of PIN is found in Shanxi Airlines, and it can be inferred that Shanxi Airlines B has the highest probability of informed trading. Air China has the highest and lowest PIN values except for Shanhang B, respectively, which is more volatile. The maximum and minimum values other than Shanhang B and Air China appear in CITIC Haizhong and Southern Airlines, respectively.

Based on the characteristics of the findings, it is reasonable to speculate that different airlines behave differently in terms of corporate governance and contribute to systematic differences in their degree of informed trading.
Table 1. Descriptive statistics table for PIN values.

\begin{tabular}{ccccc}
\hline & Mean PIN & Variance & Max & Minimum \\
\hline SA & 0.683641885 & 0.006653279 & 0.7660978 & 0.4711577 \\
EA & 0.344399777 & 0.003510734 & 0.4554824 & 0.2367609 \\
HA & 0.414965846 & 0.005429186 & 0.498115 & 0.1917995 \\
SA & 0.2832505 & 0.001322907 & 0.334407 & 0.2160098 \\
CA & 0.303990446 & 0.00650167 & 0.5103507 & 0.1428262 \\
JA & 0.300321692 & 0.00197696 & 0.3780022 & 0.2173198 \\
CH & 0.400075238 & 0.001616674 & 0.5056428 & 0.3468428 \\
SA & 0.317794446 & 0.005001812 & 0.4674465 & 0.158776 \\
AVG & 0.381054979 & 0.004001653 & 0.48944305 & 0.2476865 \\
& & & & 88 \\
\hline
\end{tabular}

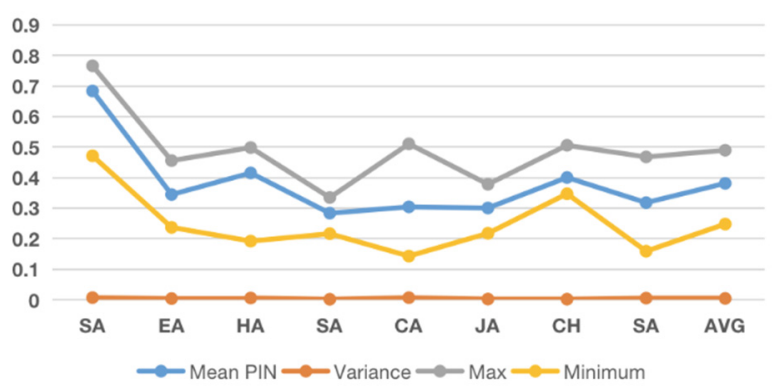

Fig. 1. Diagram of the probability of informed trading.

\section{Study Design}

\subsection{Variable Selection}

\subsubsection{Governance variable selection}

The explanatory variable proportion of informed traders (PIN) was calculated using the PIN values from the Easley, Kiefer, and O'Hara (1996) model. The explanatory variables focused on three main aspects: human capital characteristics, board characteristics, equity structure, and. Regarding human capital characteristics, they are mainly represented by two secondary indicators: the number of undergraduate students (BA_p) and management compensation (salary); regarding board characteristics, they are mainly represented by two secondary indicators: the proportion of independent directors (p_in) and board size (b_sz); regarding equity structure, they are mainly represented by two secondary indicators: the average number of shares held by households (hold_av) and the proportion of institutional holdings (hold_ $i$ ) two secondary indicators. The proportion of institutional shareholding is expressed by the sum of shareholding of funds, brokerages, brokerage houses, QFII, insurance institutions, social security funds, enterprise annuities, trusts and finance companies, and the proportion of independent directors is the proportion of independent directors to the number of directors [5].

\subsubsection{Control variable selection}

Since the effect of corporate governance level on information asymmetry is confounded by multiple factors, this paper uses whether it is a first-tier city (Region), 
whether it is a state-owned enterprise (NPR), the average of daily closing prices $(\mathrm{P})$ during the sample period and the average of daily earnings per share (EPS) during the sample period as control variables.

\subsection{Descriptive statistics of variables}

The size of PIN value indicates the severity of the occurrence of informed behavior, and the calculation shows that the maximum value of PIN value is 0.48944305 , the minimum value is 0.247686588 , and the average value is 0.381054979 , which indicates that the degree of probability of informed transactions varies significantly from company to company. In the human capital characteristics, the maximum and minimum values of the number of people with bachelor's degree and above as a percentage of management compensation are significantly different, indicating that the human capital characteristics of different companies are significantly different [6]. In the equity structure characteristics, the difference between the percentage of institutional shareholding and the percentage of household shareholding is also significant, with the maximum value of institutional shareholding being 0.782697061 , the minimum value being 0 , and the average value being 0.488266318 . Compared to the board of directors characteristics, the difference is smaller and the maximum and minimum values are relatively close.

\section{Equations and mathematics}

\subsection{Multiple regression analysis}

To examine the relationship between corporate governance and information risk of airline companies, this paper uses Bootstrap re-sampling method for regression analysis. Due to the small sample size of this paper, a total of $24 \times 39=936$ observations, the reliability of statistical inference using other distributions such as normal distribution is low, while Bootstrap can have put-back random sampling of $\mathrm{n}$ observation units contained through the original data set with small sample size to compose a new sample, expand the sample size, and calculate the mean value by repeating at least 1000 times of random sampling, and the calculated mean value contains various combinations of samples, making the results more robust and convincing, and solving the challenge of not being able to obtain large samples. The coefficient estimates of the explanatory variables through the method as above are shown in the following table.

According to the coefficient estimates of the explanatory variables, the direction of the coefficients of the variables is inconsistent and there are significant differences in the absolute values of the coefficients, which indicates that the results of the probability of informed trading, PIN, are significantly different depending on different factors. The number of shares per household (hold_av) and amplitude (stdev) are negatively related to the degree of informed trading, while management compensation (salary), board size (p_sz), turnover rate (turnover), and return on assets (roa) are positively related to the behavioral impact of informed trading.

The coefficient of human capital characteristics (salary) is 0.28 but insignificant, indicating that management compensation stock is not related to the probability of informed trading, which means that whether or not the company management adopts a system of high pay for integrity, it cannot influence the occurrence of informed trading behavior. Management often wants to obtain higher share prices to satisfy their own interests, and executives are already familiar with the company's inside information and have more professional skills and knowledge, so if they disclose insider information to other stakeholders, it will intensify the occurrence of informed trading behavior. Therefore, instead of paying higher salaries to management to avoid informed trading, companies should adopt more effective monitoring measures [7].

The coefficient of board size (p_sz) is 0.0091978 at $90 \%$ significance level, which is positive but small in absolute value, the occurrence of informed trading behavior increases with the increase of board size. The larger the size of the board of directors, the less influence individual directors have on the outcome of the decision, making decisions that are in the interest of the company compared to companies with smaller boards of directors, diminishing the impact of individuals chasing interests and making extreme decisions that result in damage to the company [8]. Therefore, independent directors will increase the occurrence of informed trading behavior.

The coefficient of hold_av is negative at $10 \%$ level of significance and the absolute value is large, the number of holdings and the probability of informed trading are negatively correlated, a decentralized shareholding structure helps to avoid the occurrence of informed trading and prevents the occurrence of informed trading.

Table 2. Bootstrap regression results.

\begin{tabular}{cccccc}
\hline & Observed & Bookstrap & & & Normal-based \\
\hline PIN & Coef. & Std. Err. & $\mathrm{z}$ & $\mathrm{P}>|\mathrm{z}|$ & {$[95 \%$ Conf.Interval] } \\
salary & 0.2801385 & 0.411381 & 0.68 & 0.496 & -0.52615351 .08643 \\
p_sz & 0.0091978 & 0.1240781 & 0.07 & 0.941 & -0.2339908 .2523865 \\
$\begin{array}{c}\text { hold_ } \\
\text { av }\end{array}$ & -3.799306 & 32.7338 & -0.12 & 0.908 & -67.9563860 .35776 \\
stdev & -0.2400433 & 0.5453271 & -0.44 & 0.660 & -1.308865 .8287781 \\
turno & 1.030289 & 3.391441 & 0.30 & 0.761 & -5.6168127 .677391 \\
ver & & & & & \\
roa & -0.0007297 & 0.302506 & -0.00 & 0.998 & -.5936307 .5921713 \\
cons & 0.2029245 & 1.458042 & 0.14 & 0.889 & -2.6547853 .060634 \\
\hline
\end{tabular}

\subsection{Robustness tests}

We use the proportion of bachelor's degree and above (ba_p) instead of management compensation (salary), the proportion of independent directors ( $p \_$in) instead of board size ( $\left.p_{-} s z\right)$, and the proportion of institutional shareholding (hold_i) instead of the average number of household shareholdings (hold_av) to denote human capital characteristics, board characteristics, and equity structure characteristics, respectively, and use the model to conduct robustness tests, which The conclusions are 
similar to the above results, the proportion of independent directors and institutional shareholding are significantly related to PIN, the proportion of independent directors is significant at $10 \%$ level of significance and the proportion of institutional shareholding is significant at $5 \%$ level of significance, and the coefficients of the alternative variables are in the same direction as the original variables, which indicates that the conclusions drawn by the model are robust. The results of the robustness tests are shown in Table 3.

Table 3. Robustness test results.

\begin{tabular}{ccccccc}
\hline & Observed & Bookstrap & & & Normal-based \\
\hline PIN & Coef. & Std. Err. & $\mathrm{z}$ & $\mathrm{P}>|\mathrm{z}|$ & {$[95 \%$ Conf.Interval] } \\
salary & 0.0081035 & 0.1075502 & 0.08 & 0.940 & -0.2026911 & 0.2188981 \\
p_sz & 1.821377 & 26.7363 & 0.07 & 0.946 & -50.58080 & 54.22356 \\
$\begin{array}{c}\text { hold_ } \\
\text { av }\end{array}$ & -0.1921344 & 8.058336 & -0.02 & 0.981 & -15.98618 & 15.60191 \\
stdev & -0.0666254 & 4.667776 & -0.01 & 0.989 & -9.215299 & 9.082048 \\
turno & 1.127821 & 42.85884 & 0.03 & 0.979 & -82.87395 & 85.12959 \\
ver & & & & & & \\
roa & 0.0084784 & 0.9723921 & 0.01 & 0.993 & -1.897375 & 1.914332 \\
cons & -0.8926935 & 18.98941 & -0.05 & 0.963 & -38.11125 & 36.32586 \\
\hline
\end{tabular}

\section{Conclusion}

This paper uses the EKOP model to directly measure the probability of informed trading PIN, and improves on it by estimating daily PIN values. The results are regressed using bookstrap to test the effects of human capital characteristics, board characteristics, and equity structure characteristics on the probability of informed trading. The empirical test proves that the effect of management compensation on informed trading behavior is not significant, so increasing management salary or employee education is not effective in reducing the probability of informed trading. Board characteristics such as larger board size and higher percentage of institutional ownership lead to more severe informed trading behavior. Stocks with higher institutional ownership and average household ownership have a lower probability of informed trading. We believe that this result is due to the fact that this paper focuses on the airline industry and does not explore the impact of other industries' shareholding structure characteristics on the probability of informed trading.

Based on the concept of green economy development and the standardized pattern of corporate governance, this paper proposes the following measures to improve the corporate governance situation.

(1) Strengthen internal corporate governance. Management compensation does not effectively influence the occurrence of informed trading, so the effective way for companies to avoid informed trading is to strengthen internal supervision, including the establishment of an internal supervisory organization, the establishment and improvement of reward and punishment mechanisms, the introduction of relevant measures in relevant company regulations, and the improvement of the internal supervision mechanism of corporate self-assessment and self-audit.
(2) Improve the shareholding structure. Select a reasonable size of the board of directors, strengthen the process of selecting and training independent directors, and strictly follow the regulations on the ratio of independent directors; carefully select institutional investors and examine the background and qualifications of the relevant institutional investors; and strictly comply with the system of separation of powers between the chairman and the general manager.

(3) Strengthen government supervision. Continuously improve the SEC's regulatory measures for companies, increase the penalties for company information disclosure or violations, and strengthen external supervision of companies through relevant policies to make auditors and others strictly enforce relevant laws and regulations.

The research in this paper confirms that the level of corporate governance has a greater impact on the degree of information asymmetry, so enterprises, the government and other departments need to strengthen the governance of companies to reduce the degree of information asymmetry, strengthen the liquidity of the financial market to maintain fair transactions.

\section{References}

1. George A. (1970) The Market for Lemons: Quality Uncertainty and the Market Mechanism. The Quarterly Journal of Economics.

2. Hasbrouck J. (1991) The Summary Informativeness of Stock Trades: An Econometric Analysis.The Review of Financial Studies, 4: 571-595.

3. Blume L, Easley D, O'Hara M. (1994) Market Statistics and Technical Analysis: The Role of Volume. The Journal of Finance, 49: 153-181.

4. Han L, Zheng J, Li D. (2008) Probability of informed trading (PIN) characteristics and risk pricing ability in Shanghai. China Management Science, 1: 16-24.

5. Yang Z, Yao S. (2004) An empirical study of bid-ask spreads and informative trading in Shanghai. Financial Research, 4: 45-56.

6. Zhang G, Liu Y. (2009) A study of securities trading direction discrimination--a method design for commission-driven continuous bidding market. Journal of Shanxi University of Finance and Economics, 31: 98-107.

7. Shen B, Ran G, Sheng J. (2012) A study of informed trading behavior based on institutional investors' capital flow. Research on finance and economics, 4 : 10-17.

8. Hui Y, Gao Y. (2018) A comparison of information asymmetry measures in Chinese stock market--a study based on the case of administrative punishment by the Securities Regulatory Commission. Securities Market Herald, 8: 47-54+64. 